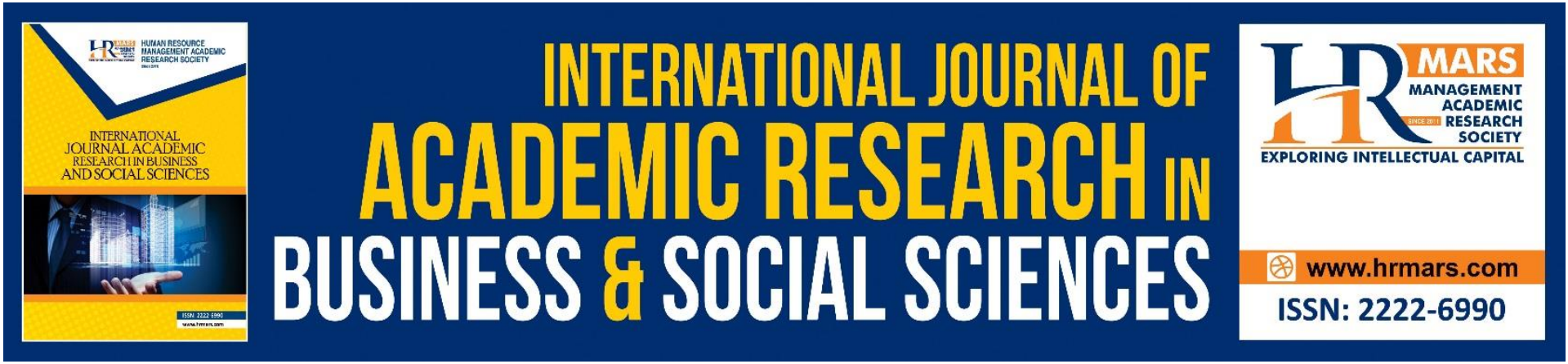

\title{
Developing the Mandarin e-Module of "Small Talk at Workplace" for MFL learners in Malaysia
}

\section{Hiang Loon Low}

To Link this Article: http://dx.doi.org/10.6007/IJARBSS/v11-i4/9836

DOI:10.6007/IJARBSS/v11-i4/9836

Received: 06 February 2021, Revised: 10 March 2021, Accepted: 29 March 2021

Published Online: 24 April 2021

In-Text Citation: (Low, 2021)

To Cite this Article: Low, H. L. (2021). Developing the Mandarin e-Module of "Small Talk at Workplace" for MFL learners in Malaysia. International Journal of Academic Research in Business and Social Sciences, 11(4), 1371-1383.

Copyright: (c) 2021 The Author(s)

Published by Human Resource Management Academic Research Society (www.hrmars.com) This article is published under the Creative Commons Attribution (CC BY 4.0) license. Anyone may reproduce, distribute, translate and create derivative works of this article (for both commercial and non-commercial purposes), subject to full attribution to the original publication and authors. The full terms of this license may be seen at: http://creativecommons.org/licences/by/4.0/legalcode

Vol. 11, No. 4, 2021, Pg. 1371 - 1383

Full Terms \& Conditions of access and use can be found at http://hrmars.com/index.php/pages/detail/publication-ethics 


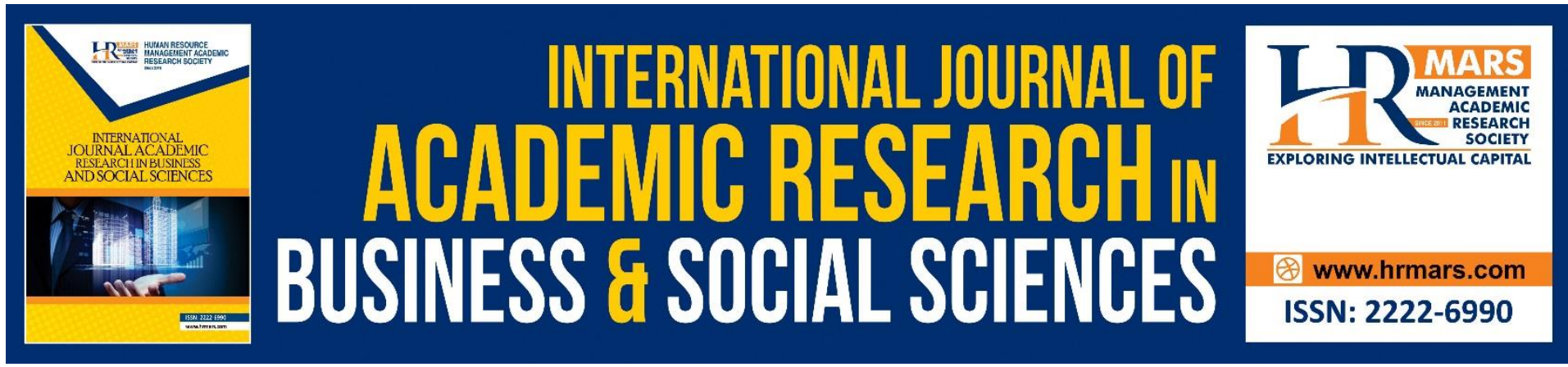

\title{
Developing the Mandarin e-Module of "Small Talk at Workplace" for MFL learners in Malaysia
}

\author{
Assoc. Prof. Dr. Hiang Loon Low \\ Akademi Pengajian Bahasa, Universiti Teknologi MARA (UiTM), Shah Alam 40450, Selangor, \\ Malaysia \\ Email: hiangloon2004@yahoo.com
}

\begin{abstract}
Research carried out in Malaysia identified that learners of Mandarin as a foreign language (MFL) in Malaysia were keen "to make small talk" and "to communicate with Mandarin speaking colleagues at workplace". However, a survey of the Mandarin learning materials available in the market indicates that there are plenty of learning materials for "General Mandarin" for daily use and materials for "Business Mandarin" but none for "Workplace Mandarin". Hence, there is an urgent need for Mandarin experts to produce suitable and comprehensive materials specifically for Mandarin for workplace communication. In contributing to the needs of "Workplace Mandarin", the Mandarin e-Module of "Small Talk at Workplace" was developed to fulfil Mandarin language learners' needs "to make small talk" and "to communicate with Mandarin speaking colleagues at workplace". For this purpose, ADDIE Model, a systematic approach consists of instructional design principles was adopted to develop the e-module of "Small Talk at Workplace". The ADDIE model consists of five phases: analysis, design, development, implementation, and evaluation. It is a strategic plan for designing an e-module and video clips incorporated with Powtoon animation were selected as the platform to deliver the e-content developed for the e-module. The completion of the Mandarin e-Module of "Small Talk at Workplace" is important as it can be marketed as an e-learning toolkit. The toolkit will help learners to make effective small talk as a social skill where effective small talk can be a useful tool to help them achieve goals they set in their work life.
\end{abstract}

Keywords: Mandarin as a Foreign Language (MFL), E-Module, Small Talk, Workplace Mandarin, ADDIE Model.

\section{Introduction}

Research carried out in Malaysia identified that learners of Mandarin as a foreign language in Malaysia were keen "to make small talk" (Low \& Goh, 2018) and "to communicate with Mandarin speaking colleagues at workplace" (Low, 2012). However, a survey of the Mandarin learning materials available in the market indicates that there are plenty of learning materials for "General Mandarin" for daily use and materials for "Business Mandarin" but none for "Workplace Mandarin" (Kinokuniya Malaysia, 2019; Popular Online, 2019). 
Hence, there is an urgent need for Mandarin experts to produce suitable and comprehensive materials specifically for Mandarin for workplace communication. In contributing to the needs of "Workplace Mandarin", the Mandarin e-Module of "Small Talk at Workplace" was developed to fulfil Mandarin language learners' needs "to make small talk" and "to communicate with Mandarin speaking colleagues at workplace".

This research has promoted on electronic learning or e-learning. E-learning means any forms of learning that are supported electronically (Jethro et al., 2012) or empowered by the use of digital technologies (Arkorful, \& Abaidoo, 2014) as e-learning has proven to be effective in many research (Al Kurdi et al., 2020; Somayeh et al., 2016; Jethro et al., 2012) for the learning of knowledge in different fields (Eiman \& Farid, 2018; O'Donnell et al., 2015; Vatsala \& Pissay, 2014) and hence e-learning has played its inevitable role especially for higher education (Pande et al., 2016; Arkorful, \& Abaidoo, 2014).

E-learning was chosen as the platform to deliver the small talk content as e-learning materials with the incorporation of multimedia elements, is widely accepted as more attractive and effective as compared to traditional static contents with only words and static images (Aeiad \& Meziane, 2019) (Norafida Ithnin \& Othman Ibrahim, 2000; Zaidatun Tasir \& Yap Sao Wen, 2000). In this development, the e-content of "small talk at workplace" was presented through a stand-alone and user-friendly e-module (Hadi et al., 2017). The self-instructed e-module will promote independent learning (Munthe et al., 2019) and allows learners to learn at anytime and at anywhere (Somayeh et al., 2016).

In creating a quality instructional e-module, this research has employed ADDIE Model, a systematic approach consists of instructional design principles (Davis, 2013) to develop the Mandarin e-module of "Small Talk at Workplace". The ADDIE model consists of five phases, however, this paper will only illustrate how the researchers carried out the first three phases of the ADDIE model, namely "Analysis, Design \& Development" (). The other phases of "implementation and evaluation" will be reported in another paper.

\section{An Overview}

\section{Why "Small Talk"?}

Before illustrating on developing the Mandarin e-module of "Small Talk at Workplace", this paper will elaborate on the importance of small talk. Small talk is defined as "light, casual, informal conversation or chitchat"; (Merriam Webster, n.d.; Frost, 2019) or "polite conversation about subjects that are ordinary or unimportant, especially at social occasions" (Oxford Advanced Learner's Dictionary, n.d.). Small talk can also be defined as informal, interpersonal or social talk at work (Coupland, 2014). It is regards as "flexible, adaptable, compressible and expandable" (Holmes, 2015).

Making small talk can help someone feeling connected to colleagues, and a good relationship can be started through small, icebreaking conversations (Globoforce, 2014). Therefore, making small talk is very important, because it is the first step to show our politeness to colleagues (Holmes \& Stubbe, 2015), where we listen to and respond to colleagues' opinions. Socialising at work is important (Pluszczyk, 2020) as if someone has done this well, he or she will seize the opportunity to leave a good impression to other colleagues (Pegler, 2019). In fact, small talk is a window of opportunity (Bissonnette, 2015), and it will help someone to 
create social connection (Markman, 2019) and build deeper relationships with colleagues in the future.

According to a survey conducted by Globoforce (2014), 89\% of respondents declared that work relationships gave an impact on their overall quality of life. Thus, in order to maintain a good work relationship, the effort of making small talk is very important, because it shows that a person has seen themselves as part of the team. Making small talk with colleagues is also the starting point for building trust (Bissonnette, 2015).

In reality, small talk is not meaningless chitchat (Jackson, 2020) but it covers a wide range of functions at the workplace (Pluszczyk, 2020; Holmes, 2005) to get things done. The functions of small talk are not limited to reaching social goals, that is, building and maintaining interpersonal social relationship through everyday conversation, but small talk has specific functions to establish rapport between professionals and clients (relational functions) to achieve transactional goals (Coupland, 2014).

However, in this research, the emphasis was only placed on social goal as to meet MFL learners' language needs to communicate with Mandarin speaking colleagues at work. To add, the e-module does not intend to prepare learners to use Mandarin small talk from 9 to 5 (Holmes, 2000) because it is a big challenge for MFL learners in Malaysia to do Mandarin small talk since majority of them are elementary learners. Hence the content selected will be limited to the most suitable topics for small talk at workplace (Frost, 2020; Frost, 2019; Coupland, 2014). Given that making small talk even with a small amount of workplace socialising, will bring benefit in many aspects (Jackson, 2020; Curley, 2018; Moon, 2017; Globoforce, 2014), the researchers embarked the journey to develop the Mandarin e-module of "Making Small Talk at Workplace" aiming to help the MFL learners in Malaysia to conduct small talk at the workplace.

\section{Why "ADDIE model"}

There are various instructional design models that can be used as a guide in designing and developing online materials. However, ADDIE model and ASSURE model are recognised as popular models to be employed by majority of the researchers. The ADDIE model is an acronym for "Analysis, Design, Develop, Implement and Evaluate" (Cheung, 2016; Branch, 2009) while the ASSURE model is an acronym for 6 stages namely "Analyse the learner, State objectives, Select media, Utilize, Require students' participation, Evaluate and revise" (Reyes \& Oreste, 2017).

However, comparing the ADDIE \& ASSURE, ADDIE model is a winning model (Karmila Rafiqah et al., 2019) mainly because it covers a wide range of situations than ASSURE (Karmila Rafiqah et al., 2019) and due to it is a non-linear process, the model allows feedback on each stage (Branch, 2009). In contrast, ASSURE is regards as more suitable to be used in classroom setting for face-to-face implementation (Nurpandi et al., 2013). As an overall, ADDIE has been widely used by many researchers to develop online learning courses in various fields (Patel et al., 2018; Hadi et al., 2017; Cheung, 2016; Durak, \& Ataizi, 2016; Davis, 2013) including education and language (Cheung, 2016). 
Hence, this research will also adopt ADDIE model to guide on developing the e-module of "Small Talk at Workplace". As mentioned earlier, ADDIE model consists of 5 phases, namely "Analysis", "Design", "Development", "Implementation", and "Evaluation" (Patelet al., 2018; Cheung, 2016; Treser, 2015; Branch, 2009). However, in this paper, the illustration will be drawn on only the first 3 phases where the outcome of the last two phases will be reported in another paper.

The "Analysis phase" identifies the needs of the learners in terms of educational goals, and based on the findings, educational objectives are set to determine what to be taught first to accomplish learners' educational goals. The "Design phase" works on producing a blueprint on how the instruction will be delivered. This involves content selection to meet educational objectives and to decide on suitable instructional strategy.

Come to "Development phase", the effort will be placed on creating and organising the actual learning material to be used when instruction is delivered. At the "Implementation phase", the well-designed instruction will be delivered for test run or for implementation. Finally, the "Evaluation" will be carried out to determine if the instruction is achieving its intended goals. Any unachieved goals should be examined on its weaknesses and changes are required to improve the instruction.

\section{Objectives}

The development of the Mandarin E-Module Of "Making Small Talk at Workplace" aims to achieve a few objectives as follows,

- It will enable learners "to make small talk" and "to communicate with Mandarin speaking colleagues at workplace" in which the specific needs were highlighted in the Mandarin language needs research (Low \& Goh, 2018; Low, 2012).

- It will broaden one's job prospect by mastering workplace communicational language in Mandarin.

- It will also strengthen learners' language skills specifically on listening and speaking Mandarin at workplace. Furthermore, the e-module will help users to enhance their social skill as Small talk is an important workplace skill. It is the first step in establishing relationships with colleagues.

- It will create enjoyable and active learning environment for learners with attractive powtoon videos.

\section{Developing The Mandarin E-Module: Methodology, Findings \& Discussions "Analysis Phase"}

The Analyze phase is the foundation for all other phases of instructional design. During this phase, several analysis were carried out including "Needs analysis", "Goal analysis", "Task analysis", "Learners' analysis" and "Performance analysis" (Cheung, 2016; Treser, 2015; Branch, 2009).

\footnotetext{
“Needs Analysis"

In determining learners' essential language needs, first of all, a specific research technique, that is, Mandarin language needs analysis was conducted in a public university in Malaysia to gather learners' views on 116 Mandarin learning goals.

Mandarin language goals of learners of Mandarin as a foreign language in Malaysia.
} 
Two categories of respondents were involved in the Mandarin language needs analysis. The first category of 149 working people were MFL learners of distance learning programmes and Language Proficiency Course of the university. The second category was 234 full time students of the Faculty of Accountancy, Faculty of Computer and Mathematical Sciences, and Faculty of Film, Theatre and Animation. All $381 \mathrm{MFL}$ students were invited to evaluate the importance of 116 Mandarin learning goals by rating 5 as "very important" and 0 as "not important".

\section{"Goal Analysis"}

After completing the "Needs analysis", the "Goal analysis" (Low \& Goh, 2018, p. 132) was carried out. The MFL learners for both categories declared their keen interest of the goal "to make small talk" besides other goals of "to get help", "to make negotiation", "to use Mandarin during interview", "to make oral report in Mandarin", "to talk about career" and "to talk on educational background" among the top 25 learning goals. Apart from these goals, the "Working People Group" informed about their wish to be able "to talk about working experience" in Mandarin as one of the top 25 goals while the "Fulltime Student Group" announced on their interest "to talk about job hunting" in Mandarin as one of the top 25 goals to be achieved.

\section{"Task Analysis"}

Examining above essential language goals proposed by MFL learners, "Task analysis" was done. Obviously the skills or knowledges of the 9 language goals that the MFL learners wanted to achieve were truly needed for the learners to function in the workplace. The "Task analysis" on the identified 9 language goals ascertained that "Workplace Mandarin" was in great demand by MFL learners and thus "Workplace Mandarin" should be taught to meet learners' language needs.

A "Learner analysis" done on both categories of respondents showed that the "fulltime Student Group" held very similar preferences and motivations with the "Working People Group" in regards to the language goals related to "Workplace Mandarin".

\section{"Performance Analysis"}

Lastly, the "Performance analysis" done to measure to what extent the existing Mandarin courses offered by the university were aligned with the language needs identified in the "Needs analysis". Unfortunately, the Mandarin syllabus delivered in the university did not place much emphasis on "Workplace Mandarin". A survey of the Mandarin content of the 3 level Mandarin courses offered revealed that none of the language goals of "Workplace Mandarin" was delivered except simple "Interview" content was taught in the Level 3 Mandarin course.

\section{Description of Constraints}

Summarising the analysis phase, researchers ascertained the MFL learners lack the skills and knowledges of "Workplace Mandarin". A survey of the Mandarin learning materials available in the market indicates that there were plenty of learning materials for "General Mandarin" for daily use and materials for "Business Mandarin" but none for "Workplace Mandarin". Hence, there is an urgent need for Mandarin experts to produce suitable and comprehensive materials specifically for Mandarin for workplace communication. 
In contributing to meet the needs of "Workplace Mandarin", "Small Talk" which will allow learners "to communicate with Mandarin speaking colleagues at workplace" (Low, 2012) was determined to be taught first to accomplish the language goals of MFL learners. These outputs of "Analysis phase" were the inputs for the next "Design phase". The Mandarin e-Module of "Small Talk at Workplace" was then developed to fulfil Mandarin language learners' needs "to make small talk" and "to communicate with Mandarin speaking colleagues at workplace".

\section{"Design Phase"}

The Design phase involves using the outputs from the Analysis phase to plan a strategy for developing the instruction. During this phase, the researchers were required to "creating a blueprint of how the instruction will be delivered" (Cheung, 2016, p. 3). To achieve this purpose, the researchers planned and outlined the flow or procedures on how to reach the instructional goals, that is, to develop the Mandarin e-Module of "Small Talk at Workplace". A few aspects were taken into account including a) setting useful, action-oriented learning objectives, and b) deciding on the optimal method or the most suitable or workable instructional strategy to guide the learning.

\section{Defining "Target Population"}

Defining "Target population": the Mandarin e-Module of "Small Talk at Workplace" was meant to guide elementary MFL learners in Malaysia who aimed to make "Small Talk" at the existing or future workplace. Although the e-module did not start the guidance from zero, any MFL learners who had knowledge for the Mandarin pronunciation system of Hanyu Pinyin will be able to follow the e-module well.

\section{Setting "Learning Objectives" \& Selecting the E-Content}

At this point, the researchers set useful learning objectives based on the content selection. To produce a high quality small talk e-content, much research (Frost, 2019; Frost, 2020; Coupland, 2014) was carried out to determine the most important content to be learnt by learners. A thorough analysis on possible topics for "Small Talk" was done.

The content selection was very important as what the learners choose to talk can make a positive first impression at the workplace. Basically, there was one main rule, that is, "common ground" (Markman, 2019) in selecting the content for the Mandarin e-module.

That common ground refers to the knowledge that both speakers and hearers are likely to share such as common interests or talk about someone both parties know in common. For example, in one dialogue of the e-module, we included the content that "the manager got a promotion yesterday" presumes that the hearer knows who the manager is and what job promotion the speaker talked about.

In brief, the conversations on "Small Talk" may relate to the work (task oriented) or may draw on topics outside of the work scope (non-task-oriented) (Markman, 2019; Holmes, 2015). "Small Talk" may draw on general, neutral and safe topics (Pegler, 2019; Moon, 2017) such as "family, hobbies, sports, food or restaurant, weather, traffic, travel, plans for the weekend", etc. "Small Talk" can also "discuss the surroundings such as the town or the city, and the life in the town or the city; discuss the entertainment such as the movies or drama series someone is watching. Last but not least, work is also a good "Small Talk" topic as most people 
like to know the work progress of another person. In regards to this topic, content such as talking about report writing, commenting on work environment, job promotion, increment of salary, working overtime, working outstation, intention to change job, resign from current job and etc. were included.

In order to help learners to familiarise with Mandarin words related to "Work topic", the content such as "'writing a report', reading a report', 'looking for information', 'chatting with colleague', 'preparing the documents', 'placing an order', "talking on promotion and salary increment", and etc. were also included in the e-module.

After researching on "Small Talk" topics, related topics to carry out specific learning objectives were selected and e-content were drafted for further action to develop 20 video clips in the "Development phase".

\section{Sequencing the Instruction}

In this research, design principle of "signaling" (Ibrahim, 2012) was applied to highlight important vocabulary in both learning focus videos and videos for conversational dialogues. To make the learning more effective, the e-module's instruction was sequenced as Step 1: Discovering "signaling" vocabulary before mastering learning focuses; and step 2: Discovering "signalling" vocabulary before enhancing conversational dialogues. In the step 1, numbers were "signaled" on several words in the conversational sentences, both in Mandarin version and English version which will appear at the same time on any "signaling" videos. In contrast to all the "signaling" videos, learners will find "nonsignaling" videos where no numbers were "signalled" in any of the "Small Talk" videos.

Learning important vocabulary through the "signaling" videos first, then proceed to mastering the learning focuses will strengthen learners' knowledge on the sentence structures that were useful for carrying out the "Small Talk". The instruction's sequence fulfils the requirement of the Schema theory. In Schema theory, a unit of knowledge is called a schema and it is made up of past knowledge (Yan, 2020). Learning is recognised as a "bottom up" process in the way that learning is "done in a fix sequence to get a word meaning gradually" (Paul \& Christopher, 2017, p. 11) which mean one will learn start from smaller units of words, then learners will relate their existing schemata and use their past knowledge to gain new knowledge (Ting \& Tai, 2004).

In short, when learners of the Mandarin e-module follow the sequence to discover words in learning focuses and words in conversational dialogues in the module, they will then proceed to learn the sentences and later the whole dialogue of a topic. The sequence above will definitely help them moving on step by step to master the e-module. The expected outcome is learners will be able to perform well when carrying out the topics of small talk that they have learned.

\section{Selecting a Delivery System}

The instructional foundation suitable for the e-module was thoroughly studied

At this level, consideration was drawn on determining which instruction was the appropriate solution to meet learners' needs to make small talk with Mandarin speaking colleagues at workplace. Solutions to the instructional problem incorporates the decision to use the 
technology that is, in this research, the employment of the Powtoon Animation Software to produce all the 20 learning videos.

In the use of instructional multimedia, namely Powtoon Animation Software, learners will be directed to watch and listen to narrated animations. The educational videos developed through Powtoon Animation Software are important to help learners acquire knowledge as they can present learning content dynamically with the use of technology such as audio and animations to catch and sustain learners' attention (Vatsala \& Pissay, 2014).

Video formats were chosen as the medium to deliver the e-content designed for the small talk e-module as video format has increased its importance as a popular form of delivering information. The usefulness of video clips is supported by the cognitive theory of multimedia learning that learners retain more knowledge from words and pictures than words alone (Nicholas, 2020, 371).

\section{"Development Phase"}

After deciding on the strategy for the instructional delivery and creating the educational objectives, the "Development phase" emphasis on producing and organising the learning contents to be used during the instruction. In creating a good e-module, two design principles were employed to prepare the learning materials.

\section{Design Principle of "Segmentation"}

Segmentation refers to dividing learning materials into smaller units such as topics or lessons (Ibrahim, 2012). In the research, segmentation principle was adopted where all selected content for "Small Talk" was divided into 10 topics. The segmentation principle was further applied where all selected sentence structures were further divided into 10 different learning focuses. Presentation of each learning focus was aligned with the segmentation principle where in a short video, there were 4-5 examples for each learning focus and learners were allowed to pause at anytime between different segments. Segmentation on learning material will greatly benefit learners as it allows learners to learn by their own pace and to digest new knowledge part by part.

\section{Design Principle of "Signaling"}

There are various technics to be used when creating instructional tool using the design principle of signalling. For example, highlighting some content such as changing words' font style, bold certain words, adding outline and headings, giving same color to related elements, and etc. In this research, design principle of "signaling" was applied to highlight important vocabulary in both learning focus videos and videos for conversational dialogues. Design principle of signalling was proven to be useful to attract learners' attention in the process of learning with audiovisual materials such as through video as an instructional tool (Ibrahim, 2012; Mautone \& Mayer, 2001).

\section{Adopting "Listening" and "Asking" Skills}

Apart from above design principles, the creation of the e-module was also adopted the "listening" and "asking" skills (Pegler, 2019) for the learning materials. Paying attention to what people talked about or doing active listening will help us knowing their interested topics for making small talk (Pegler, 2019). 
When small talk starts, besides elaborating one's own thought, it is important to generate questions. Asking insightful questions is a great way to show that you're really paying attention. Hence, in delivering the learning focuses of the e-module, most of the content was presented in Q \& A format to help learners practising "listening" and "asking" skills in making small talk. Once learners have mastered all learning focuses, they will come to the next stage, that is, learning the 10 conversational dialogues of making small talk. Most of the dialogues were also presented with the format of $Q \& A$ to help learners making small talk.

After all content was developed, audio recording on voice over was carried out in the studio and finally the creation of Powtoon animation for 20 videos was successfully completed by the researchers of the project according to the designed content.

\section{Conclusion}

The Mandarin e-Module of "Small Talk at Workplace" was developed to fulfil Mandarin language learners' needs "to make small talk". ADDIE Model, a systematic approach consists of instructional design principles was adopted to develop the e-module of small talk. This paper illustrates how the e-module was developed based on the first three phases of "Analysis, Design \& Development" of the ADDIE model. The other phases of "implementation and evaluation" will be reported in another paper.

ADDIE Model, the Father of all instructional design models" (Apostolopoulos, 2021) has provided the theoretical framework to the Mandarin e-Module of "Small Talk at Workplace". With the guidance of this theoretical framework, language needs of learners of Mandarin as a Foreign Language in Malaysia were analysed in the first phase of the process of "Analysing". The identification of the language needs of "Mandarin for workplace" was significant as it has highlighted the insufficient learning materials of "Mandarin for workplace" in Malaysia. With the success of completing the process of "Designing" and "Developing" for the Mandarin eModule of "Small Talk at Workplace", the methodology of the research can be replicated by future researchers to develop more e-modules on "Mandarin for workplace" to meet the language needs of MFL learners in Malaysia.

\section{References}

Aeiad, E., Meziane, F. (2019). An adaptable and personalised E-learning system applied to computer science Programmes design. Education and Information Technologies, 24, 1485-1509. https://doi.org/10.1007/s10639-018-9836-x

Al Kurdi, B., Alshurideh, M., \& Salloum, S. S. (2020). Investigating a theoretical framework for e-learning technology acceptance. International Journal of Electrical and Computer Engineering (IJECE), 10(6), 6484 - 6496. http://doi.org/10.11591/ijece.v10i6.pp64846496.

Apostolopoulos, A. (2021). ADDIE training model: What is it and how to use it in elearning. https://www.talentlms.com/blog/addie-training-model-definition-stages/

Arkorful, V., \& Abaidoo, N. (2014). The role of e-learning, the advantages and disadvantages of its adoption in Higher Education. International Journal of Education and Research, 2(12), 397-410.

Bissonnette, B. (2015). The importance of small talk at work. United States, Greater Boston, MA, Forward Motion Coaching.

https://www.forwardmotion.info/wp/the-importance-of-small-talk-at-work/ 
Branch, R. M. (2009). Instructional Design: The ADDIE Approach. New York: Springer.

Cheung, L. (2016). Using the ADDIE model of instructional design to teach chest radiograph interpretation. Journal of Biomedical Education, 2016, 1-6.

Coupland, J. (Ed.). (2014). Small Talk. United Kingdom: Routledge.

Curley, M. (2018). BIG Benefits of Small Talk In The Workplace. https://www.business2community.com/human-resources/big-benefits-of-small-talkin-the-workplace-02098547

Davis, A. (2013). Using instructional design principles to develop effective information literacy instruction: The ADDIE model. College \& Research Libraries News, 74(4), 205-207. doi:https://doi.org/10.5860/crln.74.4.8934.

Durak, G., \& ataizi, M. (2016). The ABC's of Online Course Design According to Addie Model. Universal Journal of Educational Research, 4(9), 2084-2091.

Eiman, A., \& Farid, M. (2018). An adaptable and personalised E-learning system applied to computer science Programmes design. Education and Information Technologies. 28 Nov 2018. DOI: 10.1007/s10639-018-9836-x.

Frost, A. (2019). The ultimate guide to small talk: conversation starters, powerful questions, \& more. Ireland, Dublin, HubSpot. https://blog.hubspot.com/sales/small-talk-guide

Frost, A. (2020). 48 questions that' II make awkward small talk so much easier. United States, Daily Muse Inc.

https://www.themuse.com/advice/48-questions-thatll-make-awkward-small-talk-somuch-easier

Globoforce. (2014). Fall 2014 research report: The effect of work relationships on organizational culture and commitment. United States, Massachusetts, Globoforce.http://go.globoforce.com/rs/globoforce/images/Fall_2014_Mood_Tracker .pdf

Holmes, J. (2005). When small talk is a big deal: Sociolinguistic challenges in the workplace. In M. H. Long (Ed.), Second language needs analysis (pp. 344-372). Cambridge, United Kingdom: Cambridge University Press.

Holmes, J. (2000). Talking English from 9 to 5: Challenges for ESL learners at work. International Journal of Applied Linguistics, 10(1), 125-140.

Holmes, J., \& Stubbe, M. (2015). Power and politeness in the workplace. New York: Routledge. Ibrahim, M. (2102). Implications of designing instructional video using Cognitive Theory of multimedia learning. Critical Questions in Education, 3(2), 83-104. https://eric.ed.gov/?id=EJ1047003

Jackson, R. (2020). The benefits of making small talk at work. https://bigthink.com/personalgrowth/small-talk-work-productivity?rebelltitem=3\#rebelltitem3.

Jethro, O. O., Grace, A. M., \& Thomas, A. K. (2012). E-learning and its effects on teaching and learning in a global age. International Journal of Academic Research in Business and Social Sciences, 2(1), 203-210.

Kinokuniya Malaysia. (2019). A search on books related to Mandarin Chinese. https://malaysia.kinokuniya.com/products?utf8=\%E2\%9C\%93\&is_searching=true\&res trictBy\%5Bavailable_only\%5D $=1 \&$ keywords $=$ mandarin\&taxon $=\& \mathrm{x}=0 \& \mathrm{y}=0$

Low, H. L. (2012). Towards a Chinese vocabulary list for learners of Mandarin as a foreign language at tertiary level in Malaysia: A needs-based study [Unpublished doctoral dissertation]. University of Otago, Dunedin, New Zealand. 
Markman, A. (2019). 4 reasons why it pays to get better at small talk. https://www.fastcompany.com/90388411/4-reasons-why-it-pays-to-get-better-atsmall-talk.

Mautone, P. D., \& Mayer, R. (2001). Signaling as a Cognitive Guide in Multimedia Learning. Journal of Educational Psychology, 93(2), 377-389. DOI: 10.1037/0022-0663.93.2.377

Moon, L. (2017). The surprising cognitive benefits of small talk at work. https://blog.trello.com/surprising-cognitive-benefits-of-small-talk-at-

work\#: :text=Recent\%20studies\%20point\%20to\%20the,watercooler\%20conversation \%20itself\%20is\%20evolving.

Munthe, E. A., Silaban, S., \& Muchtar, Z. (2019). Discovery Learning Based E-Module on Protein Material Development. Conference: Proceedings of the 4th Annual International Seminar on Transformative Education and Educational Leadership (AISTEEL 2019), Advances in Social Science, Education and Humanities Research (Series), 384, 604-607. DOI: 10.2991/aisteel-19.2019.137

Muruganantham, G. (2015). Developing of e-content package by using ADDIE model. International Journal of Applied Research, 1(3): 52-54. ISSN Print: 2394-7500 ISSN Online: 2394-5869.

Nicholas, A. (2020). Applying the cognitive theory of multimedia learning: Using the ADDIE model to enhance instructional video. Explorations in Media Ecology, 19(3), 371-380. DOI: https://doi.org/10.1386/eme_00054_1

Nurpandi, F., Langi, A. Z. R., \& Bandung, Y. (2013). Using instructional design model to implement open lesson with lesson study approach for online teacher community. 2013 Joint International Conference on Rural Information \& Communication Technology and Electric-Vehicle Technology (rICT \& ICeV-T), Bandung, 2013, 1-4, doi: 10.1109/rICTICeVT.2013.6741562.

O'Donnell, E., Lawless, S., Sharp, M., \& Wade, V. P. (2015). A Review of Personalised ELearning: Towards Supporting Learner Diversity. International Journal of Distance Education Technologies, 13(1), 22-47. DOI: 10.4018/ijdet.2015010102.

Pande, D., Wadhai, V. M., \& Thakare, V. M. (2016). E-Learning System and Higher Education. International Journal of Computer Science and Mobile Computing, 5(2), 274-280. https://www.ijcsmc.com/docs/papers/February2016/V5I2201639.pdf

Patel, S. R., Margolies, P. J., Covell N. H., Lipscomb C., Dixon L. B. (2018). Using Instructional Design, Analyze, Design, Develop, Implement, and Evaluate, to Develop e-Learning Modules to Disseminate Supported Employment for Community Behavioral Health Treatment Programs in New York State. Frontiers in Public Health, 6, 1-113.

Paul, X. J., \& Christopher, G. (2017). Teaching reading skill using heuristic technique through Schema theory. The IUP Journal of English Studies, 12(1), 11-15, Available at SSRN: https://ssrn.com/abstract=3191829

Pegler, L. (2019). The importance of small talk and how to perfect it. TheStartup, Medium's largest active publication. https://medium.com/swlh/the-importance-of-small-talkand-how-to-perfect-it-5685fb611083

Pluszczyk, A. (2020) Socializing at Work-An Investigation of Small Talk Phenomenon in the Workplace. In: Michalik U., Zakrajewski P., Sznicer I., Stwora A. (eds) Exploring Business Language and Culture. Second Language Learning and Teaching. Springer, Cham. https://doi.org/10.1007/978-3-030-58551-8_12

Popular Online. (2019). A search on books related to Mandarin Chinese. 
https://www.popularonline.com.my/cnsimplified/catalogsearch/result/index/?catego ry_id=5897\&did=8\&limit=120\&mode=grid $\& q=$ mandarin

Reyes, Y., \& Oreste, J. (2017). Acceptability level of developed material (SAI) using ASSURE model. The Educational Review, USA, 1(3), 61-69. https://doi.org/10.26855/er.2017.03.003

Somayeh, M., Dehghani, M., Mozaffari, F., Ghasemnegad, S. M., Hakimi, H., \& Samaneh, B. (2016). The effectiveness of E- learning in learning: A review of the literature. International Journal of Medical Research \& Health Sciences, 5(2), 86-91.

Ting, R. Y., \& Tai, Y. (2004). The Design of Computer Multimedia Material for English Language Learning. ROCLING. https://www.semanticscholar.org/paper/The-Design-ofComputer-Multimedia-Material-for-TingTai/6d9d94ebf32684486f7ced3b4113425b9d76d924

Treser, M. (2015). Getting to know ADDIE: Part 1 - Analysis. https://elearningindustry.com/getting-know-addie-analysis

Treser, M. (2015). Getting to know ADDIE: Part 2 - Design. https://elearningindustry.com/getting-to-know-addie-design

Treser, M. (2015). Getting to know ADDIE: Part 3 - Development https://elearningindustry.com/getting-to-know-addie-development

Treser, M. (2015). Getting to know ADDIE: Part 4 - Implementation. https://elearningindustry.com/getting-know-addie-implementation

Treser, M. (2015). Getting to know ADDIE: Part 5 - Evaluation https://elearningindustry.com/getting-know-addie-evaluation

Vatsala, L., \& Pissay, S. (2014). Preferences of Adult E-Learners towards Online Resources. Nitte Management Review, 8(2): 115-125. http://informaticsjournals.com/index.php/index/search/search

Yan, N. (2020). A Brief Analysis of the Schema Theory on the Teaching of English Reading. Proceedings of the International Conference on Modern Educational Technology and Innovation and Entrepreneurship (ICMETIE 2020).

https://doi.org/10.2991/assehr.k.200306.108 